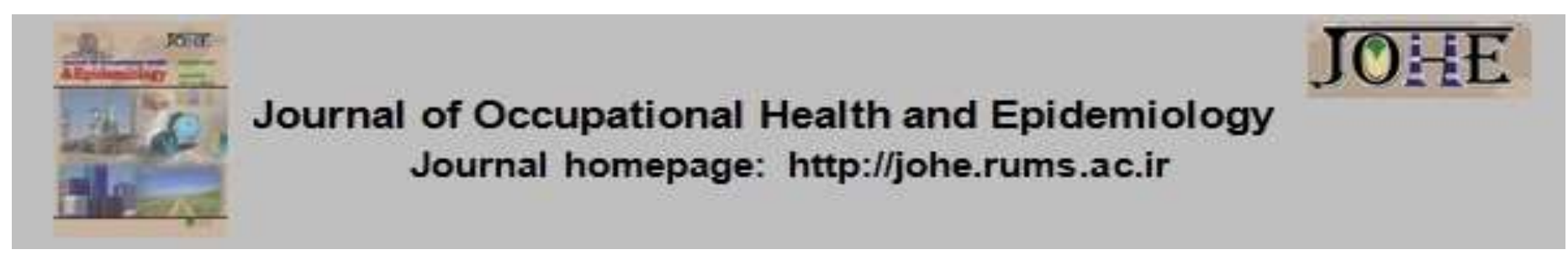

\title{
Musculoskeletal disorder and its correlation with the awareness of ergonomics factors in nurses working at some university hospitals, Tehran, Iran (2018)
}

\author{
Somayeh Farhang Dehghan ${ }^{1}$, Rohollah Fallah Madvari², Elham Akhlaghi Pirposhte ${ }^{3}$, Abbas \\ Mohammad Hosseini ${ }^{3}$, Fereydoon Laal ${ }^{4}$ \\ 1. Assistant Prof., Department of Occupational Health, School of Public Health and Safety, Shahid Beheshti University of Medical \\ Sciences, Tehran, Iran. \\ 2. Instructor, Department of Occupational Health, Shahid Sadoughi University of Medical Sciences, Yazd, Iran. \\ 3. Instructor, Department of Occupational Health, School of Public Health and Safety, Shahid Beheshti University of Medical \\ Sciences, Tehran, Iran. \\ 4. Student Research Committee, Department of Occupational Health, School of Public Health and Safety, Shahid Beheshti University \\ of Medical Sciences, Tehran, Iran.
}

Citation: Farhang S, Fallah Madvari R, Akhlaghi Pirposhte E, Mohammad Hosseini A, Laal
F. Musculoskeletal disorder and its correlation with the awareness of ergonomics factors in
nurses working at some uiversity hospitals, Tehran, Iran (2018). JOHE. 2019; 8(1):37-42.

Article Info

*Corresponding author:
Fereydoon Laal,
E-mail:
fereydoonlaal@gmail.com

Article history

Received: Aug, 2018

Accepted: Jan, 2019

10.29252/johe.8.1.37

Print ISSN: 2251-8096 Online ISSN: 2252-0902

Peer review under responsibility of Journal of Occupational Health and Epidemiology

\section{Abstract}

Background: Work-related musculoskeletal disorders (WMSDs) are from among the most prevalent occupational health problems leading to high costs and reduced productivity in nurses. Therefore, the present study aimed at investigating musculoskeletal disorders (MSDs) in nurses and their correlation with demographic factors and awareness of ergonomics at the selected hospitals of Shahid Beheshti University of Medical Sciences in 2018.

Materials and Methods: This descriptive study was performed on 150 nurses of the selected hospitals of Shahid Beheshti University of Medical Sciences. Research data were collected using the Cornell Musculoskeletal Discomfort Questionnaire (CMDQ) and the ergonomic knowledge questionnaire. In addition, descriptive statistics, the KolmogorovSmirnov test, the Chi-square test, and the Spearman's test were used to analyze the data. Results: The mean and standard deviation of the age and work experience of the participants were $32.67 \pm 8.63$ and $7.44 \pm 8.84$ years, respectively. Approximately $67.3 \%$ (101 individuals) had a bachelor's degree. According to the results, the average level of the nurses' awareness of ergonomics, working conditions, and occupational injuries were $3.14 \pm 0.72$ (medium level), $0.68 \pm 2.58$ (very weak level), and $0.95 \pm 2.10$ (very weak level), respectively. The awareness of ergonomics and working conditions in all areas had a significant negative correlation with the severity of discomfort $(p<0.05)$.

Discussion: The results showed that the nurses' awareness of ergonomics and working conditions were medium and poor, respectively. In addition, it was demonstrated that the use of ergonomic interventions to improve working conditions could play a significant role in reducing the nurses' occupational injuries.

Keywords: Musculoskeletal Disorders, Awareness, Nurses, Hospitals

\section{Introduction}

Ergonomics is the science of identifying the physical and mental abilities as well as limitations of humans, which plays a significant role in designing and applying industrial systems and tools with which people deal on a daily basis (1). Musculoskeletal disorders (MSDs) are the most prevalent causes of work-related disabilities, being responsible for $65 \%$ of occupational diseases $(2,3)$. MSDs are from among the most worrisome health issues in the world, which are common in almost all occupations in all people with inappropriate postures at work (4). It has been reported that MSDs cause discomfort and pain in the muscles and bones of the lower back, shoulders, arms, and hands, being probably the cause of an increase in the risk of herniated discs (5). MSDs are from among the major occupational health issues in healthcare workers (6). Studies conducted on various occupations show that nursing is one of the ten major 
occupations, which cause musculoskeletal disorders (7). Due to the nature of its work, the nursing occupation at hospitals is one of the jobs in which work-associated musculoskeletal disorders are more prevalent than the majority of other occupations (8). In addition, given nurses' job conditions, they are responsible for performing important tasks, such as providing psychological and physical care, which require the long-term flexion of their bodies (9).

Occupational injuries, especially muscular ones, are the major causes of disabilities in healthcare personnel around the world (10). In a study conducted by Sheikhzadeh et al., they concluded that work-related musculoskeletal disorders (WMSDs), especially the lower back pain, were common in operating room nurses (11).

There is a number of work-related factors in almost every workplace that threatens employees' health and safety. These factors threaten the health conditions of nursing personnel at hospitals and clinics where there is a high level of physical and mental demands (12). Hence, in order to maintain an acceptable level of work performance, it is necessary to organize and plan for appropriate occupations based on scientific methods. Ergonomics is the science that helps improve employees' health and well-being by designing work tasks, tools, and equipment, as well as assigning appropriate tasks to people at work $(1,3)$. Therefore, the present study was conducted aimed at investigating musculoskeletal disorders in nurses and its relationship with demographic factors, awareness of ergonomics, and working conditions.

\section{Materials and Methods}

This descriptive study was conducted in 2018 . The study population consisted of 150 nurses working at the selected hospitals of Shahid Beheshti University of Medical Sciences. From among the hospitals of Shahid Beheshti University of Medical Sciences, four hospitals (Taleghani, Shohadaye Tajrish, Imam Hossein, and Modarres) were selected randomly. Using the following formula, the sample size ( $n$ ) was estimated at 150 with the confidence level of $95 \%$, according to the prevalence of disorders $(P=0.66)$ in the study by Ashghali Farahani (13). In addition, the precision (d) value in this study was 0.075 .

$$
\mathrm{n}=\frac{\mathrm{z}_{\left(1-\frac{a}{2},\right)}^{2} \mathrm{P}(1-\mathrm{P})}{\mathrm{d}^{2}}
$$

The inclusion criteria consisted of at least one year of work experience and written informed consent for participation in the research. In addition, the exclusion criteria included having a second job, drug addiction, a spinal surgery history, osteoporosis, arthritis, work-related occupational accidents, and the history of specific diseases, such as diabetes and heart diseases. The nurses who met the qualification criteria were included in the study and signed the informed consent form. Data were collected using the Cornell Musculoskeletal Discomfort Questionnaire (CMDQ) and the ergonomic knowledge questionnaire. The CMDQ questionnaire is a data collection tool for the study of musculoskeletal disorders developed by Professor Alan Hedge and his ergonomic students (1999), which has so far been used in several studies $(8,14,15)$. The validity and reliability of the mentioned questionnaire have been confirmed in various studies. In addition, the validity and reliability of the Persian version of the questionnaire was examined by Afifehzadeh-Kashani (16). The Cornell questionnaire is divided into three parts, including the frequency of feeling pain and discomfort, the severity of feeling pain and discomfort, and the effect of feeling pain and discomfort on the working ability, which has a body map and analyzes 12 body organs. In this study, a standard questionnaire was used to assess the level of knowledge and occupational injuries. This questionnaire, in each part, specified the frequency or severity of pain and did not have a specific scale. The validity and reliability of this questionnaire were confirmed in the study by Mosaddegh Rad (2004) (17).

Besides, to classify the nursing personnel's awareness of ergonomics, working conditions, and job injuries, the scores obtained were grouped as follows:

Scores less than 2 were very weak, 2 to 2.75 were weak, 2.76 to 3.5 were medium, 3.51 to 4.25 were good, and 4.26 to 5 were very good (17).

The Kolmogorov-Smirnov test was used to assess the normal distribution of data. The correlation between nominal and ordinal variables was assessed using the Chi-square and spearman tests. In addition, the significance level was considered at 0.05 , in this study.

\section{Results}

In the present study, the total number of the subjects was 150, with the mean and standard deviation of the age and work experience of the participants having been about $32.67 \pm 8.63$ and $7.44 \pm 8.84$ years, respectively. Most of the subjects were female $(72.7 \%, 109$ people) and single (51.3\%, 77 people). Approximately $67.3 \%$ (101 people) of the participants had a bachelor's degree. According to the results, the mean level of the nurses' awareness of ergonomics, working conditions, and occupational injuries, such as MSDs, were $3.14 \pm$ 
0.72 (medium level), $0.68 \pm 2.58$ (very weak level), and $0.95 \pm 2.10$ (very weak level), respectively. Table 1 shows the amount and severity of discomfort in various human body organs, according to the Cornell questionnaire. In addition, the severity of discomfort is seen in Table 1 at low, medium, and high levels. According to table 1, in the regions of hip, forearms and upper arms, the least amount of discomfort has occurred. The results also showed that discomfort was more severe in the lower legs, knees, and lower back regions.

Table 1: The frequency and percentage of feeling pain and discomfort in body parts in nurses working at the selected hospitals of Shahid Beheshti University of Medical Sciences in 2018

\begin{tabular}{|c|c|c|c|c|c|c|c|c|}
\hline \multirow{2}{*}{ Organ } & \multicolumn{5}{|c|}{ Frequency of feeling pain and discomfort $\mathrm{N}(\%)$} & \multicolumn{3}{|c|}{$\begin{array}{c}\text { Severity of feeling Pain and } \\
\text { discomfort } \mathrm{N}(\%) \\
\end{array}$} \\
\hline & Never & $\begin{array}{l}\text { 1-2 times } \\
\text { a week }\end{array}$ & $\begin{array}{l}\text { 3-4 times } \\
\text { a week }\end{array}$ & $\begin{array}{c}\text { Once a } \\
\text { day }\end{array}$ & $\begin{array}{c}\text { Several } \\
\text { times a day }\end{array}$ & Low & Medium & High \\
\hline Neck & $27(18)$ & $50(33.3)$ & $25(16.7)$ & $24(16)$ & $24(16)$ & $47(31.3)$ & $76(50.7)$ & $27(18)$ \\
\hline Shoulders & $47(31.3)$ & $34(22.7)$ & $17(11.3)$ & $26(17.3)$ & $26(17.3)$ & $60(40)$ & $63(42)$ & $27(18)$ \\
\hline Upper back & $34(27.7)$ & $45(30)$ & $13(8.7)$ & $24(16)$ & $34(22.7)$ & $55(36.7)$ & $59(39.3)$ & $36(24)$ \\
\hline Upper arms & $76(50.7)$ & $32(21.3)$ & $10(6.7)$ & $14(9.3)$ & $18(12)$ & $84(56)$ & $47(31.3)$ & 19(12.7) \\
\hline Lower back & $39(26)$ & $29(19.3)$ & $43(28.7)$ & $12(8)$ & $27(18)$ & $56(37.3)$ & $57(38)$ & $37(24.7)$ \\
\hline Forearms & $85(56.7)$ & $26(17.3)$ & $16(10.7)$ & $14(9.3)$ & $9(6)$ & $88(58.7)$ & $54(36)$ & $8(5.3)$ \\
\hline Wrists & $63(42)$ & 29(19.3) & $20(13.3)$ & 16(10.7) & $22(14.7)$ & $78(52)$ & $52(34.7)$ & $20(13.3)$ \\
\hline Hands/fingers & $72(48)$ & $27(18)$ & $23(15.3)$ & $12(8)$ & $16(10.7)$ & $89(59.3)$ & $44(29.3)$ & $17(11.3)$ \\
\hline Hip & $84(56)$ & $40(26.7)$ & $7(4.7)$ & $14(9.3)$ & $5(3.3)$ & $97(64.7)$ & $40(26.7)$ & $13(8.7)$ \\
\hline Thighs & $75(50)$ & $28(18.7)$ & $25(16.7)$ & $9(6)$ & $13(8.7)$ & $79(52.7)$ & $56(37.3)$ & $15(10)$ \\
\hline Knees & $38(25.3)$ & $26(17.3)$ & $27(18)$ & $19(12.7)$ & $40(26.7)$ & $55(36.7)$ & $54(36)$ & $41(27.3)$ \\
\hline Lower legs & $41(27.3)$ & $29(19.3)$ & $26(17.3)$ & $17(11.3)$ & $37(24.7)$ & $56(37.4)$ & $46(30.7)$ & $48(32)$ \\
\hline
\end{tabular}

According to Table 2, the greatest effects of pain and discomfort on the nurses' working ability were exerted on the neck (33.3\%), lower legs (31.3\%), knees (27.3\%), and the upper back (26.0\%), respectively.

Table 2: The effects of feeling pain and discomfort on the working ability of various human body organs in the nurses working at the selected hospitals of Shahid Beheshti University of Medical Sciences in 2018

\begin{tabular}{lccc}
\hline \multirow{2}{*}{ Organ } & \multicolumn{2}{c}{ The effects of feeling pain and discomfort on the working ability (\%) } \\
\cline { 2 - 4 } & Never & Low & High \\
\hline Neck & $38(25.3)$ & $62(41.3)$ & $50(33.3)$ \\
\hline Shoulders & $48(32)$ & $65(43.3)$ & $37(24)$ \\
\hline Upper back & $45(30)$ & $66(44)$ & $39(26)$ \\
\hline Upper arms & $81(54)$ & $50(33.3)$ & $19(12.7)$ \\
\hline Lower back & $50(33.3)$ & $68(45.3)$ & $32(21.3)$ \\
\hline Forearms & $95(63.3)$ & $46(30.7)$ & $9(6)$ \\
\hline Wrists & $79(52.7)$ & $52(34.7)$ & $19(12.7)$ \\
\hline Hands/fingers & $82(54.6)$ & $52(34.7)$ & $16(10.7)$ \\
\hline Hip & $88(58.6)$ & $49(32.7)$ & $13(8.7)$ \\
\hline Knees & $77(51.4)$ & $61(40.7)$ & $12(8)$ \\
\hline Lower legs & $44(29.4)$ & $65(43.3)$ & $41(27.3)$ \\
\hline
\end{tabular}

The results showed a significant negative correlation between the awareness of ergonomics and occupational injuries $(P<0.001, r=0.436)$. Besides, there was a significant negative correlation between working conditions and occupational injuries $(P=0.00, r=0.357)$.

In addition, table 3 shows a correlation between the severity of discomfort in different human body organs and demographic information (gender and marital status as well as the education level), the awareness of ergonomics, and working conditions. According to this table, there is no significant correlation between the severity of discomfort in almost all human body organs and the awareness of ergonomics. The only significant negative correlation was observed between the severity of discomfort in upper arms and awareness of ergonomics ( $P=0.001, r=-0.266)$. Unlike the awareness of ergonomics, working conditions in almost all human body organs had a significant negative correlation with the severity of discomfort. Besides, there was no significant correlation between demographic information and the severity of discomfort in various body organs, except for the correlation between the severity of discomfort at the lower back and the education level. 
Table 3: The correlation of musculoskeletal disorders with the awareness of ergonomics and demographic factors in nurses in 2018

\begin{tabular}{|c|c|c|c|c|c|c|}
\hline $\begin{array}{l}\text { Discomfort in the } \\
\text { body }\end{array}$ & $\begin{array}{c}\text { Awareness of } \\
\text { ergonomics }\end{array}$ & $\begin{array}{c}\text { Working } \\
\text { conditions }\end{array}$ & $\begin{array}{c}\text { Occupational } \\
\text { injuries }\end{array}$ & Gender & $\begin{array}{c}\text { Marital } \\
\text { status }\end{array}$ & $\begin{array}{c}\text { Education } \\
\text { level }\end{array}$ \\
\hline Neck & Ns & $\begin{array}{c}r=-0.270^{* *} \\
p=0.001\end{array}$ & Ns & Ns & Ns & Ns \\
\hline Shoulder & Ns & $\begin{array}{c}r=-0.254^{\star *} \\
p=0.002\end{array}$ & $\begin{array}{l}r=0.231^{* *} \\
p=0.004\end{array}$ & Ns & Ns & Ns \\
\hline Upper back & Ns & $\begin{array}{l}r=-0.197^{*} \\
p=0.016\end{array}$ & Ns & Ns & Ns & Ns \\
\hline Upper arms & $\begin{array}{c}r=-0.266^{* \star} \\
p=0.001\end{array}$ & $\begin{array}{l}r=-0.313^{* *} \\
p=0.000\end{array}$ & Ns & Ns & Ns & Ns \\
\hline Lower back & Ns & Ns & $\begin{array}{c}r=0.273^{\star *} \\
p=0.001\end{array}$ & Ns & Ns & $\begin{array}{l}r=0.165^{\star} \\
p=0.043\end{array}$ \\
\hline Forearms & Ns & $\begin{array}{l}r=-0.202^{*} \\
p=0.013\end{array}$ & Ns & Ns & Ns & Ns \\
\hline Wrists & Ns & Ns & Ns & Ns & Ns & Ns \\
\hline Hands/fingers & Ns & Ns & Ns & Ns & Ns & Ns \\
\hline Hip & Ns & $\mathrm{Ns}$ & Ns & Ns & Ns & Ns \\
\hline Thighs & Ns & $\begin{array}{c}r=-0.275^{\star *} \\
p=0.001\end{array}$ & $\begin{array}{l}r=0.200^{*} \\
p=0.014\end{array}$ & Ns & Ns & Ns \\
\hline Knees & Ns & $\begin{array}{l}r=-0.187^{*} \\
p=0.022\end{array}$ & Ns & Ns & Ns & Ns \\
\hline Lower legs & $\mathrm{Ns}$ & $\mathrm{Ns}$ & $\mathrm{Ns}$ & $\mathrm{Ns}$ & $\mathrm{Ns}$ & $\mathrm{Ns}$ \\
\hline
\end{tabular}

Spearman and Pearson correlations were used, respectively.

\section{Discussion}

The results of this study showed that the levels of the nurses' awareness of ergonomics and working conditions were medium and poor, respectively. In addition, the significant negative correlation of working conditions and knowledge of ergonomics with occupational injuries in various body organs was confirmed. In fact, if the nurses' working conditions were not appropriate, the degree of disturbance and discomfort in different body organs would increase; in addition, with an increase in the awareness of ergonomics, the damage would decrease. Poor working conditions make personnel face more risk factors, such as adverse work postures, increased exposure to harmful biological agents, contact with sharp devices, and the manual handling of patients, being inconsistent with the results of the studies in the United States, Canada, Finland, Sweden, and the United Kingdom (18-20). Zakerian also concluded that the nurses' knowledge of the principles of ergonomics was moderate, and the working conditions as well as the extent of occupational injuries were also weak (21).

Ergonomics is the understanding of the interaction between humans and other elements of a system. Therefore, without an appropriate ergonomic design, long-term work can lead to MSDs in work environments. In the present study, the highest severity of discomfort was observed in the lower legs, knees, and the lower back, with the highest effects of pain and discomfort on the nurses' work ability having been in the neck, lower legs, knees, and the upper back, which could be due to the prolonged standing as well as the handling and transporting of people in a non-standard way. Studies by Niosh (22), Smedley et al. (23), Dohayuge Kee, and Sun Rim Seo (24) point to the prevalence of MSDs in nurses as well. According to the study by Dohayuge Kee and Sun Rim Seo, the shoulder, knees, and waist are more susceptible to these disorders than other organs, with this finding been almost the same as that of the present study (24). The Niosh organization, in its studies on healthcare workers, concluded that this statistical society was facing a large number of musculoskeletal disorders, especially in the neck and shoulder regions (22). The study by Smedley et al. showed a high rate of musculoskeletal disorders in the shoulder and neck regions (23). In a study conducted by Fanello et al. in France, the use of ergonomic interventions and training programs led to a significant decrease in pain in the nurses' back and waist regions (25).

It is suggested that the senior managers of hospitals and universities of medical sciences provide more support for ergonomic intervention studies, aimed at improving nurses' working conditions. The results of the present study can help healthcare managers and authorities make wise decisions on improving nurses' working conditions. The uncooperativeness of some nurses due to high workload and the failure to complete some questionnaires were from among the limitations of the present study. After explaining the importance of the study, some participants agreed to cooperate in the research. It is suggested that healthcare managers pay more attention to the discipline of ergonomics. As already noted, training 
sessions and ergonomic interventions are helpful in this area. It is also suggested that nurses' anthropometric issues as well as their work environments be considered in future research.

\section{Conclusion}

The results showed that the nurses' awareness of ergonomics and working conditions were medium and poor, respectively. From among the factors effective in reducing nurses' occupational injuries, one can refer to making use of integrated and comprehensive training programs to increase nurses' awareness of the principles and rules of ergonomics, familiarizing nurses with the principles of body mechanics, establishing ergonomic committees on hospital risk assessments, identifying people susceptible to musculoskeletal risk factors, hiring people in jobs tailored to their individual abilities, and using ergonomic interventions to improve work conditions and environments.

\section{Acknowledgement}

This study is concerned with the project number $66108 / 1396$, by the Student Research Committee, Shahid Beheshti University of Medical Sciences, Tehran. We would like to express our especial thanks to the Student Research Committee and the Research and Technology Chancellor of Shahid Beheshti University of Medical Sciences for their financial support for this study.

\section{Conflict of interest: None declared.}

\section{References}

1. Gavgani VZ, Nazari J, Jafarabadi MA, Rastegari F. Is librarians' health affected by ergonomic factors at the work place? Library Philosophy and Practice [Internet]. Jan 2013. Available from: http://digitalcommons.unl.edu/libphilprac/893

2. Wahlström J. Ergonomics, musculoskeletal disorders and computer work. Occup Med (Lond) 2005; 55(3):168-76.

3. Buckle P. Ergonomics and musculoskeletal disorders: overview. Occup Med (Lond) 2005; 55(3):164-7.

4. Smith DR, Leggat PA, Speare R. Musculoskeletal disorders and psychosocial risk factors among veterinarians in Queensland, Australia. Aust Vet J 2009; 87(7):260-5.

5. Sadri GH. A model of bus drivers' diseases: risk factors and bus accidents. Iran J Med Sci 2002; 27(1):39-41.

6. Feng $Q$, Liu S, Yang L, Xie M, Zhang Q. The prevalence of and risk factors associated with musculoskeletal disorders among sonographers in Central China: A cross-sectional study. PloS One 2016; 11(10): e0163903.

7. Gholami M, Kavousi A, Saremi M. Identification and prioritization of the factors associated with musculoskeletal disorders in nurses at a Specialized hospital. Iranian Journal of Ergonomics 2016; 4(2):44-51.

8. Menzel NN, Brooks SM, Bernard TE, Nelson A. The physical workload of nursing personnel: association with musculoskeletal discomfort. Int J Nurs Stud 2004; 41(8):859-67.

9. Abedini R, Choobineh A, Hasanzadeh J. Musculoskeletal load assessment in hospital nurses with patient transfer activity. International Journal of Occupational Hygiene 2013; 5(2):3945.

10. Jahanpour F, Khalili A, Pouladi Sh, Zoladl $M$, Dehghanian $\mathrm{H}$. Construction and evaluation of nursing ethics questionnaire. Armaghane Danesh Journal 2014; 19(9):788-96.

11. Sheikhzadeh A, Gore C, Zuckerman JD, Nordin $M$. Perioperating nurses and technicians' perceptions of ergonomic risk factors in the surgical environment. Appl Ergon 2009; 40(5):833-9.

12. Abdollahzade F, Mohammadi F, Dianat I, Asghari E, Asghari-Jafarabadi M, Sokhanvar Z. Working posture and its predictors in hospital operating room nurses. Health Promot Perspect 2016; 6(1):17-22.

13. Ashghali Farahani $M$, Shahryari M, Saremi M, Mohammadi N, Haghani $H$. Effectiveness of patient handling training on musculoskeletal disorders of nurses assistance. Iran Journal of Nursing 2017; 30(107):10-9.

14. Hedge A, Morimoto S, Mccrobie D. Effects of keyboard tray geometry on upper body posture and comfort. Ergonomics 1999; 42(10):1333-49.

15. Jansen K, Luik M, Reinvee M, Viljasoo V, Ereline $\mathrm{J}$, Gapeyeva H, et al. Musculoskeletal discomfort in production assembly workers. Acta Kinesiologiae Universitatis Tartuensis 2012; 18:102-10.

16. Afifehzadeh-Kashani $H$, Choobineh $A$, Bakand $\mathrm{SH}$, Gohari MR, Abbastabar H, Moshtaghi P. Validity and reliability of farsi version of Cornell Musculoskeletal Discomfort Questionnaire (CMDQ). Iran Occupational Health Journal 2011; 7(4):69-75.

17. Mosadeghrad AM. Relationship between nurses' knowledge about ergonomy and their job injuries. Journal of Shahrekord University of Medical Sciences 2004; 6(3):21-32.

18. Punnett L, Wegman DH. Work-related musculoskeletal disorders: the epidemiologic evidence and the debate. $\mathrm{J}$ Electromyogr Kinesiol 2004; 14(1):13-23

19. North F, Syme SL, Feeney A, Head J, Shipley MJ, Marmot MG. Explaining socioeconomic differences in sickness absence: the Whitehall II Study. BMJ 1993; 306(6874):361-6.

20. Leijon M, Hensing G, Alexanderson K. Gender trends in sick-listing with musculoskeletal symptoms in a Swedish county during a period of rapid increase in sickness absence. Scand $\mathrm{J}$ Soc Med 1998; 26(3):204-13.

21. Zakeriyan A, Monazam MR, Habibi Mohrez M, Soltani Gerdfaramarzi R, Asghari M, Ghaemiyan $\mathrm{N}$. Relationship between knowledge of ergonomics and work-place conditions with musculoskeletal disorders among nurses of two Iranian hospitals. Occupational Medicine Quartely Journal 2012; 3(4):19-25.

22. Waters T, Collins J, Galinsky T, Caruso C. $\mathrm{NIOSH}$ research efforts to prevent 
musculoskeletal disorders in the healthcare industry. Orthop Nurs 2006; 25(6):380-9.

23. Smedley J, Inskip H, Trevelyan F, Buckle P, Cooper C, Coggon D. Risk factors for incident neck and shoulder pain in hospital nurses. Occup Environ Med 2003; 60(11):864-9.

24. Kee D, Seo SR. Musculoskeletal disorders among nursing personnel in Korea. Int $\mathrm{J}$ Ind Ergon 2007; 37(3):207-12.

25. Fanello S, Jousset N, Roquelaure Y, ChotardFrampas V, Delbos V. Evaluation of a training program for the prevention of lower back pain among hospital employees. Nurs Health Sci 2002; 4(1-2):51-4. 